\title{
Device Dislodged or Dislocated
}

National Cancer Institute

\section{Source}

National Cancer Institute. Device Dislodged or Dislocated. NCI Thesaurus. Code C62950.

Problems associated with the device not remaining in an expected location. 